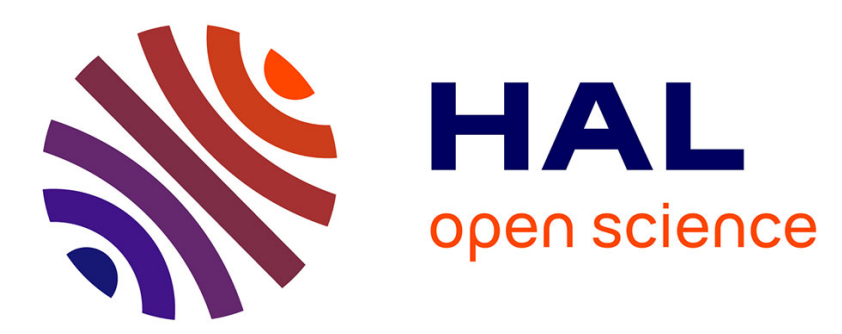

\title{
Association of interleukin-17A polymorphisms with the risk of colorectal cancer: A case-control study
}

Sinda A Bedoui, Mouadh Barbirou, Mouna Stayoussef, Meriem Dallel, Amina

Mokrani, Lamia Makni, Amel Mezlini, Balkiss Bouhaouala, Besma

Yacoubi-Loueslati, Wassim Almawi

\section{To cite this version:}

Sinda A Bedoui, Mouadh Barbirou, Mouna Stayoussef, Meriem Dallel, Amina Mokrani, et al.. Association of interleukin-17A polymorphisms with the risk of colorectal cancer: A case-control study. Cytokine, 2018, 110, pp.18-23. 10.1016/j.cyto.2018.04.017 . pasteur-02009143

\section{HAL Id: pasteur-02009143 \\ https://hal-riip.archives-ouvertes.fr/pasteur-02009143}

Submitted on 6 Feb 2019

HAL is a multi-disciplinary open access archive for the deposit and dissemination of scientific research documents, whether they are published or not. The documents may come from teaching and research institutions in France or abroad, or from public or private research centers.
L'archive ouverte pluridisciplinaire HAL, est destinée au dépôt et à la diffusion de documents scientifiques de niveau recherche, publiés ou non, émanant des établissements d'enseignement et de recherche français ou étrangers, des laboratoires publics ou privés. 


\title{
Association of interleukin-17A polymorphisms with the risk of colorectal cancer: A case-control study
}

\author{
Sinda A. Bedoui ${ }^{\mathrm{a}}$, Mouadh Barbirou ${ }^{\mathrm{a}, \mathrm{b}}$, Mouna Stayoussef ${ }^{\mathrm{a}}$, Meriem Dallel $^{\mathrm{c}}$, Amina Mokrani $^{\mathrm{d}}$, \\ Lamia Makni $^{\mathrm{a}}$, Amel Mezlini ${ }^{\mathrm{d}}$, Balkiss Bouhaouala ${ }^{\mathrm{b}, \mathrm{e}}$, Besma Yacoubi-Loueslati ${ }^{\mathrm{a}}$, \\ Wassim Y. Almawi ${ }^{\mathrm{a}, \mathrm{f}, *}$ \\ ${ }^{a}$ Department of Biology, Faculty of Sciences of Tunis, Laboratory of Mycology Pathologies and Biomarkers, El Manar University, Tunis LR16ES05, Tunisia \\ ${ }^{\mathrm{b}}$ Laboratory of Venoms and Therapeutic Molecules, Pasteur Institute of Tunis, Tunisia \\ ${ }^{\mathrm{c}}$ Laboratory of Human Genome and Multifactorial Diseases (LR12ES07), University of Monastir, Monastir, Tunisia \\ d Salah Azeiz Oncology Institute, Tunis, Tunisia \\ ${ }^{\mathrm{e}}$ Medical School of Tunis, University of Tunis El Manar, Tunisia \\ ${ }^{\mathrm{f}}$ School of Pharmacy, Lebanese American University, Byblos, Lebanon
}

\section{A R T I C L E I N F O}

\section{Keywords:}

Colorectal cancer

Genotype

Haplotype

Interleukin-17

Polymorphism

\begin{abstract}
A B S T R A C T
Background: Interleukin (IL)-17A is proinflammatory cytokine produced by Th17 cells, which play key, but sometimes inconsistent role in autoimmunity and cancer. Polymorphic variants in $I L-17 A$ gene were differentially associated with susceptibility to cancer, including colorectal cancer (CRC).

Aim: We investigated the association between six $I L-17 A$ gene variants (rs3819024, rs2275913, rs3819025, rs10484879, rs7747909, and rs3748067) with CRC susceptibility in Tunisians.

Subjects and Methods: Retrospective case-control study. Study subjects comprised 293 patients with CRC, and 268 age-, gender-, and BMI-matched healthy controls. IL-17A genotyping was done by real-time PCR, with defined clusters.

Results: Of the seven tested $I L-17 A$ tag-SNPs, minor allele frequency (MAF) of rs10484879 was significantly higher in CRC patients than control subjects. Heterozygous rs10484879 [OR (95\% CI) = 2.63 (1.64-4.21)] was associated with higher risk, while carriage of heterozygous rs3748067 genotype was associated with reduced risk of CRC [OR $(95 \% \mathrm{CI})=0.56(0.37-0.84)]$, respectively. Carriage of rs 10484879 minor allele correlated with positive family history of CRC and other cancers $(P=0.002)$, CRC staging $(P=0.044)$, CRC treatment $(P=0.038)$, and with chemo body reaction $(P=0.001)$. Of the $7 I L-17 A$ variants, 4 were in linkage disequilibrium, hence allowing for construction of 4-locus haplotypes. Varied linkage disequilibrium (LD) was noted between the even tested $I L-17 A$ variants, and further analysis was limited to only 4-locus (rs3819024rs2275913- rs10484879-rs7747909). Haploview analysis identified the 4-locus $I L-17 A$ haplotypes AGTG $(P<0.011)$, and GATG $(P=0.036)$ to be positively associated with CRC, after controlling key covariates.

Conclusion: $I L-17 A$ rs10484879 SNP, and $I L-17 A$ haplotypes AGGTG and GAGTG constitute independent factors of CRC susceptibility. We propose that IL-17A may be a target for future CRC immunotherapy.
\end{abstract}

\section{Introduction}

Colorectal cancer (CRC) is a malignant tumor of the large intestine with rising frequency worldwide, and a major global public health concern $[1,2]$. With approximately 608,000 deaths attributed to it worldwide, CRC accounts for $8 \%$ of all cancer deaths, and is numerically the fourth common cause of cancer deaths [2]. The prevalence of CRC is estimated at $6.3 / 100,000$ per year in Tunisia [3], with comparable incidence in males and females. The diagnosis CRC is made on clinical (abdominal examination, palpation of the lymph nodes, and colonoscopic examination of the interior colon and rectum) [4,5], and laboratory findings (blood in the stool, ACE, CA19-9) [6]. While its exact causes are still poorly understood, several modifiable (lifestyle, inflammatory diseases, microbiota imbalance) [7-9], and non-modifiable factors contribute to CRC pathogenesis. The latter include ethic/ racial background, and polymorphic variants in inflammatory

\footnotetext{
Abbreviations: BMI, body-mass index; CRC, colorectal cancer; IL-17, interleukin-17; LD, linkage disequilibrium; MAF, minor allele frequency; SNP, single nucleotide polymorphisms * Corresponding author at: Faculte' des Sciences de Tunis, Universite' de Tunis El Manar, 2092 Manar II, Tunis, Tunisia.

E-mail address: wassim.almawi@lau.edu.lb (W.Y. Almawi).
} 
mediators, including cytokine [10-12].

Interleukin (IL)17 is a 155 amino acids pro-inflammatory cytokine, and is produced by Th17 cells $[13,14]$. IL-17 belongs to family of six homologous proteins, designated IL-17A through IL-17F [15,16], of which IL-17A and IL-17F are the most investigated. Several factors trigger the release of IL-17, including IL- 6 and TGF- $\beta$, which stimulate the differentiation of $\mathrm{CD}^{+}{ }^{+} \mathrm{T}$ cells into IL-17-producing Th17 cells $[13,14,17]$. Functionally, IL-17 induces the production of pro-inflammatory chemokines and cytokines, including IL-1, IL-6, TNF- $\alpha$, GCFS. These bind high-affinity receptors on epithelial cells, endothelial cells, fibroblasts and other immune cells, and trigger a local inflammatory response $[13,18]$. IL-17 production is tightly regulated, and over-production of IL-17 induces a state of low-grade chronic inflammation [18], associated with a myriad of pathologies, including allergies, celiac disease, and cancers, including colorectal cancer $[15,19-21]$.

Recently, it was suggested that elevated levels of IL-17A-producing cells are associated with poor prognosis of CRC, principally resulting from increased VEGFA expression [22-24]. IL-17A gene is located on chromosome 6 ( $6 \mathrm{p} 12.2)$, and contains 3 exons and 2 introns spanning $4252 \mathrm{bp}$. Several polymorphic variants in $I L-17 A$ gene were reported, of which some were functional. A recent Tunisian study involving 102 CRC patients demonstrated positive association of rs2275913 minor (A) allele with increased susceptibility to CRC, and with CRC-associated features, such as tumor localization, tumor differentiation, and TNM stage [10]. A similar study on Chinese patients confirmed the positive association of rs2275913 with increased susceptibility to colorectal [19] and other cancers $[15,20,24]$. As other variants in $I L-17 A$ may be associated with CRC susceptibility, here we investigated the association of six polymorphic variants in $I L-17 A$ gene with the presence of CRC and accompanying features, in Tunisian population comprising of 294 patients with CRC, and 263 healthy cancer-free control subjects.

\section{Subjects and Methods}

\subsection{Study subjects}

This was a retrospective case-control study, performed at the outpatient oncology service of Saleh Azeiz Hospital (Tunis, Tunisia). Between February 2014 to October 2016, 294 subjects with CRC (mean age $58.8 \pm 14.4$ years), and 263 cancer-free control women (mean age $57.2 \pm 18.1$ years), comprising university and hospital employees, or volunteer women, were recruited into the study. None of control subjects reported personal or family history of CRC, and were matched to CRC cases according to self-declared ethnic origin. CRC assessment was based on clinical examination, colonoscopy, and histopathology on isolated biopsies; all cases had these tests done.

Demographic and clinical information were collected for CRC patients from clinical records, and by personal interview using a unified questionnaire by referring physician. These included gender, age at study entry and at CRC diagnosis, anemia, hypertension, and smoking history. Detailed histological assessment (differentiation status), tumor localization (rectum or colon/sigmoid), and treatment were recorded for all patients. The study was done according to Helsinki II declaration, and approved by the research \& ethics committees of Saleh Azeiz Hospital and El Manar University in Tunis; all participants provided informed consent.

\subsection{IL-17A genotyping}

We identified six single nucleotide polymorphisms (SNP) in $I L-17 A$ gene with a minor allele frequency (MAF) $\geq 5 \%$, which were reported in the literature with clinical relevance using NCBI Entrez Gene SNP Geneview. IL-17A genotyping was done by VIC- and FAM-labelled allelic discrimination method, using assay-on-demand TaqMan assays ordered from Applied Biosystems (Foster City, NJ). The reaction was
Table 1

Characteristics of study participants.

\begin{tabular}{|c|c|c|c|}
\hline Parameter & Cases & Controls & $P^{\mathrm{a}}$ \\
\hline Gender (M:F) ${ }^{\mathrm{b}}$ & $\begin{array}{l}139 \text { (47.4): } 154 \\
(52.6)\end{array}$ & $\begin{array}{l}126(47.0): 142 \\
(53.0)\end{array}$ & 0.933 \\
\hline Age $(y r)^{c}$ & $58.8 \pm 14.4$ & $57.2 \pm 18.1$ & 0.247 \\
\hline BMI $\left(\mathrm{kg} / \mathrm{m}^{2}\right)^{\mathrm{c}}$ & $25.1 \pm 5.0$ & $25.0 \pm 2.8$ & 0.807 \\
\hline Anemia $^{\mathrm{b}}$ & $59(20.1)$ & $30(11.2)$ & 0.005 \\
\hline Hypertension $^{\mathrm{b}}$ & $67(22.9)$ & $45(20.0)$ & 0.453 \\
\hline Smoking ${ }^{\mathrm{b}}$ & $102(34.8)$ & $70(26.1)$ & 0.028 \\
\hline $\begin{array}{l}\text { Tumor localization }{ }^{\mathrm{b}} \text { : } \\
\text { rectum }\end{array}$ & $106(38.0)$ & NA & NA \\
\hline Colon and Sigmoid & $173(62.0)$ & NA & NA \\
\hline Differentiation $^{\mathrm{b}}$ : Poor & $88(31.7)$ & NA & NA \\
\hline Moderate & $119(42.8)$ & NA & NA \\
\hline Treatment $^{\mathrm{b}}$ : Chemotherapy & $199(74.5)$ & NA & NA \\
\hline Radiotherapy & $2(0.7)$ & NA & NA \\
\hline $\begin{array}{l}\text { Chemotherapy } \\
\text { + radiotherapy }\end{array}$ & $64(24.0)$ & NA & NA \\
\hline Surgery & $2(0.7)$ & NA & NA \\
\hline Mixed & 31 10.4) & NA & NA \\
\hline
\end{tabular}

a Student's t-test (continuous variables), Pearson's chi square test (categorical variables).

b Mean \pm SD.

c Number of subjects (percent total).

performed in $6 \mu$ l volume on StepOne Plus real-time PCR system, according to manufacturer's instructions (Applied Biosystems). Replicate blinded quality control samples were included to check for the reproducibility of the genotyping results; concordance was $>99 \%$. The average successful genotyping rate for each sample and SNP was $97.9 \%$.

\subsection{Statistical analysis}

Statistical analysis was performed by SPSS version 23 (IBM; Armonk, NY). Continuous data were presented as mean $\pm \mathrm{SD}$, and categorical variables were listed as percent of total. Student's $t$-test, and Pearson $\chi^{2}$ test was used for assessment of differences in means and inter-group significance, respectively. Power calculation was done by Genetic Power Calculator (http://pngu.mgh.harvard.edu/ purcell/cgibin/cc2k.cgi). The parameters used were 294 CRC patients and 263 control subjects, minor allele frequency (MAF) for the tested variants in CRC patients, estimated prevalence of CRC in Tunisia, along with genotypic relative risk for heterozygote $(1 / 2)$ and minor allele homozygous $(2 / 2)$. Assuming these parameters, the overall average power was calculated at $69.1 \%$.

Haploview 4.2 (www.broad.mit.edu/mpg/ haploview) was used in testing Hardy-Weinberg equilibrium (HWE). Frequencies for Caucasians (CEU), African Americans of the American Southwest (ASW) and Yoruban in Ibadan, Nigeria (YRI) were obtained from HapMap release \#28, for comparison of allele frequencies obtained in this study to those previously reported. All analyses were performed under the assumption of additive genetic effect. Haploview 4.2 was used to check linkage disequilibrium (LD) between SNPs, and haplotype patterns. IL-17A haplotypes was reconstructed by the expectation maximization method. Of the possible $64 I L-17 A$ haplotypes, 9 were found to be common (frequency $>1.5 \%$ ), and were included in further analysis. Taking control group as reference, logistic regression analysis was used for determining odds ratios (OR) and 95\% confidence intervals (95\%CI) associated with CRC risk. Statistical significance set at $P<0.05$.

\section{Results}

\subsection{Study subjects}

The demographics and clinical characteristics of study participants 
Table 2

Distribution of $I L-17 A$ alleles in colorectal cancer cases and control subjects.

\begin{tabular}{|c|c|c|c|c|c|c|c|c|c|}
\hline SNP & Position $^{\mathrm{a}}$ & Alleles & Cases MAF & Controls MAF & HWE & $\chi^{2}$ & $P$ & $\mathrm{aOR}^{\mathrm{b}}(95 \% \mathrm{CI})$ & Power \% \\
\hline rs3819024 & 52185988 & $\mathrm{~A}: \mathrm{G}$ & $131(0.223)$ & 117 (0.219) & 0.43 & 0.02 & 0.887 & $1.02(0.77-1.36)$ & 54.6 \\
\hline rs2275913 & 52186235 & $\mathrm{G}: \mathrm{A}$ & $107(0.183)$ & $77(0.145)$ & 0.28 & 2.90 & 0.089 & $1.32(0.96-1.82)$ & 73.1 \\
\hline rs3819025 & 52186476 & $\mathrm{G}: \mathrm{A}$ & $95(0.162)$ & $83(0.155)$ & 0.10 & 0.10 & 0.758 & $1.05(0.76-1.45)$ & 57.3 \\
\hline rs10484879 & 52187159 & $\mathrm{C}: \mathrm{T}$ & $98(0.167)$ & $52(0.097)$ & 0.35 & 11.76 & $6.00 \times 10^{-4}$ & $1.86(1.30-2.67)$ & 99.6 \\
\hline rs7747909 & 52189451 & $\mathrm{G}: \mathrm{A}$ & $92(0.156)$ & $101(0.188)$ & 0.10 & 2.02 & 0.156 & $0.80(0.59-1.09)$ & 64.8 \\
\hline rs3804513 & 52188399 & $\mathrm{~A}: \mathrm{T}$ & $45(0.08)$ & $28(0.07)$ & 0.08 & 0.16 & 0.689 & $1.11(0.68-1.80)$ & 71.2 \\
\hline rs3748067 & 52190541 & $\mathrm{G}: \mathrm{A}$ & $92(0.156)$ & $100(0.187)$ & 0.07 & 1.79 & 0.180 & $0.81(0.59-1.10)$ & 62.8 \\
\hline
\end{tabular}

MAF, Minor allele frequency; HWE, Hardy-Weinberg Equilibrium.

a Location on chromosome based on dbSNP build 125 .

b aOR $=$ adjusted OR, adjusted for anemia and smoking.

Table 3

IL-17A Genotype frequencies.

\begin{tabular}{|c|c|c|c|c|c|c|c|c|c|}
\hline & $1 / 1^{\mathrm{a}}$ & & & $1 / 2^{\mathrm{a}}$ & & & $2 / 2^{\mathrm{a}}$ & & \\
\hline SNP & Cases & Controls & $P$ & Cases & Controls & OR $(95 \% \mathrm{CI})$ & Cases & Controls & OR $(95 \% \mathrm{CI})$ \\
\hline rs3819024 & $177(0.60)^{\mathrm{b}}$ & $167(0.63)$ & 0.39 & $103(0.35)$ & $80(0.30)$ & $1.21(0.85-1.74)$ & $14(0.05)$ & $17(0.06)$ & $0.78(0.37-1.63)$ \\
\hline rs2275913 & $199(0.68)$ & $194(0.74)$ & 0.27 & $79(0.27)$ & $58(0.22)$ & $1.33(0.90-1.97)$ & $14(0.05)$ & $9(0.03)$ & $1.52(0.64-3.59)$ \\
\hline rs3819025 & $213(0.72)$ & $192(0.72)$ & 0.69 & $67(0.23)$ & $64(0.24)$ & $0.94(0.64-1.40)$ & $14(0.05)$ & $9(0.03)$ & $1.40(0.59-3.31)$ \\
\hline rs10484879 & $184(0.67)$ & $220(0.83)$ & $<0.001$ & $84(0.31)$ & $39(0.15)$ & $2.58(1.68-3.95)$ & $7(0.03)$ & $6(0.02)$ & $1.39(0.46-4.22)$ \\
\hline rs7747909 & $211(0.72)$ & $182(0.69)$ & 0.17 & $74(0.25)$ & $66(0.25)$ & $0.97(0.66-1.42)$ & $9(0.03)$ & $17(0.06)$ & $0.46(0.20-1.05)$ \\
\hline rs3748067 & $213(0.72)$ & $192(0.72)$ & 0.69 & $67(0.23)$ & $64(0.24)$ & $0.94(0.64-1.40)$ & $14(0.05)$ & $9(0.03)$ & $1.40(0.59-3.31)$ \\
\hline
\end{tabular}

Boldface indicates statistically significant differences.

a Genotypes were coded as per " 1 " = major allele, " 2 " = minor allele.

b Number of subjects (frequency).

Table 4

Effects of $I L-17 A$ SNP genotypes on the risk of CRC according to the different genetic models.

\begin{tabular}{|c|c|c|c|c|c|c|c|c|c|}
\hline & \multicolumn{3}{|c|}{ Codominant Model } & \multicolumn{2}{|l|}{ Dominant Model } & \multicolumn{2}{|l|}{ Recessive Model } & \multicolumn{2}{|c|}{ Log additive } \\
\hline & Genotype & P-value ${ }^{a}$ & OR $(5 \% \mathrm{CI})^{\mathrm{a}}$ & P-value ${ }^{a}$ & OR $(5 \% \mathrm{CI})$ & P-value ${ }^{a}$ & OR ( $5 \% \mathrm{CI})$ & P-value ${ }^{a}$ & OR $(5 \% \mathrm{CI})$ \\
\hline \multirow[t]{3}{*}{ rs2275913 } & $\mathrm{G} / \mathrm{G}$ & 0.29 & 1.00 (Reference) & $\mathrm{G} / \mathrm{G} v s . \mathrm{G} / \mathrm{A}+\mathrm{A} / \mathrm{A}$ & & $\mathrm{G} / \mathrm{G}+\mathrm{G} / \mathrm{A} v s . \mathrm{A} / \mathrm{A}$ & & 0.12 & $1.30(0.93-1.81)$ \\
\hline & $\mathrm{G} / \mathrm{A}$ & & $1.36(0.89-2.09)$ & 0.12 & $1.38(0.92-2.07)$ & 0.50 & $1.37(0.54-3.46)$ & & \\
\hline & $\mathrm{A} / \mathrm{A}$ & & $1.48(0.58-3.77)$ & & & & & & \\
\hline \multirow[t]{3}{*}{ rs3819024 } & $\mathrm{A} / \mathrm{A}$ & 0.52 & 1.00 (Reference) & $\mathrm{A} / \mathrm{A} v s . \mathrm{A} / \mathrm{G}+\mathrm{G} / \mathrm{G}$ & & $\mathrm{A} / \mathrm{A}+\mathrm{A} / \mathrm{G} v s . \mathrm{G} / \mathrm{G}$ & & 0.93 & $1.01(0.75-1.37)$ \\
\hline & $\mathrm{A} / \mathrm{G}$ & & $1.17(0.79-1.73)$ & 0.62 & $1.10(0.76-1.59)$ & 0.41 & $0.72(0.33-1.56)$ & & \\
\hline & $\mathrm{G} / \mathrm{G}$ & & $0.76(0.34-1.67)$ & & & & & & \\
\hline \multirow[t]{3}{*}{ rs7747909 } & $\mathrm{G} / \mathrm{G}$ & 0.20 & 1.00 (Reference) & $\mathrm{G} / \mathrm{G} v s . \mathrm{G} / \mathrm{A}+\mathrm{A} / \mathrm{A}$ & & $\mathrm{G} / \mathrm{G}+\mathrm{G} / \mathrm{A} v s . \mathrm{A} / \mathrm{A}$ & & 0.28 & $0.84(0.61-1.15)$ \\
\hline & $\mathrm{G} / \mathrm{A}$ & & $1.02(0.67-1.56)$ & 0.60 & $0.90(0.61-1.34)$ & $0.07^{3}$ & $0.46(0.19-1.09)$ & & \\
\hline & $\mathrm{A} / \mathrm{A}$ & & $0.46(0.19-1.10)$ & & & & & & \\
\hline \multirow[t]{3}{*}{ rs3819025 } & $\mathrm{G} / \mathrm{G}$ & 0.48 & 1.00 (Reference) & $\mathrm{G} / \mathrm{G} v s . \mathrm{G} / \mathrm{A}+\mathrm{A} / \mathrm{A}$ & & $\mathrm{G} / \mathrm{G}+\mathrm{G} / \mathrm{A} v s . \mathrm{A} / \mathrm{A}$ & & 0.93 & $1.01(0.73-1.41)$ \\
\hline & $\mathrm{G} / \mathrm{A}$ & & $0.86(0.57-1.31)$ & 0.74 & $0.94(0.63-1.39)$ & 0.32 & $1.62(0.61-4.30)$ & & \\
\hline & $\mathrm{A} / \mathrm{A}$ & & $1.56(0.59-4.16)$ & & & & & & \\
\hline \multirow[t]{3}{*}{ rs3748067 } & $\mathrm{G} / \mathrm{G}$ & 0.003 & 1.00 (Reference) & & $\mathrm{G} / \mathrm{G} v s . \mathrm{G} / \mathrm{A}+\mathrm{A} / \mathrm{A}$ & & $\mathrm{G} / \mathrm{G}+\mathrm{G} / \mathrm{A} v s . \mathrm{A} / \mathrm{A}$ & 0.33 & $0.85(0.61-1.18)$ \\
\hline & $\mathrm{G} / \mathrm{A}$ & & $0.56(0.37-0.84)$ & 0.04 & $0.67(0.45-0.99)$ & 0.04 & $2.83(0.93-8.60)$ & & \\
\hline & $\mathrm{A} / \mathrm{A}$ & & $2.42(0.79-7.40)$ & & & & & & \\
\hline \multirow[t]{3}{*}{ rs3804513 } & $\mathrm{A} / \mathrm{A}$ & 0.13 & 1.00 (Reference) & $\mathrm{A} / \mathrm{A} v s . \mathrm{A} / \mathrm{T}+\mathrm{T} / \mathrm{T}$ & & $\mathrm{A} / \mathrm{A}+\mathrm{A} / \mathrm{T} v s . \mathrm{T} / \mathrm{T}$ & & 0.74 & $1.07(0.71-1.62)$ \\
\hline & $\mathrm{A} / \mathrm{T}$ & & $0.64(0.33-1.23)$ & 0.71 & $0.90(0.51-1.58)$ & 0.13 & $2.27(0.73-7.08)$ & & \\
\hline & $\mathrm{T} / \mathrm{T}$ & & $2.19(0.70-6.83)$ & & & & & & \\
\hline \multirow[t]{3}{*}{ rs10484879 } & $\mathrm{C} / \mathrm{C}$ & $<0.001$ & 1.00 (Reference) & $\mathrm{G} / \mathrm{G} v s . \mathrm{G} / \mathrm{A}+\mathrm{A} / \mathrm{A}$ & & $\mathrm{G} / \mathrm{G}+\mathrm{G} / \mathrm{A} v s . \mathrm{A} / \mathrm{A}$ & & $<0.001$ & 1.99 (1.34-2.95) \\
\hline & $\mathrm{C} / \mathrm{T}$ & & $2.63(1.64-4.21)$ & $<0.001$ & $2.43(1.55-3.79)$ & 0.97 & $1.02(0.32-3.27)$ & & \\
\hline & $\mathrm{T} / \mathrm{T}$ & & $1.27(0.40-4.08)$ & & & & & & \\
\hline
\end{tabular}

Boldface indicates statistically significant differences.

a Models controlled for gender, BMI, anemia, and smoking.

are shown in Table 1. Mean age at entry of study, gender, body-mass index (BMI), and hypertension were comparable between CRC patients and control subjects. Significant differences between CRC cases and controls were noted in the number of smokers $(P=0.028)$, and incidence of anemia $(P=0.005)$. Accordingly, we selected these as the main covariates that we controlled for in subsequent analysis. Most CRC cases involved the colon and sigmoid (62\%), and most were treated with chemotherapy (74.5\%).

\subsection{Association studies}

The genotype distributions of the tested $I L-17 A$ variants were in HWE among study subjects (Table 2). MAF of the tested $I L-17 A$ variants in CRC patients and control subjects are presented in Table 2. Of the $I L$ - 


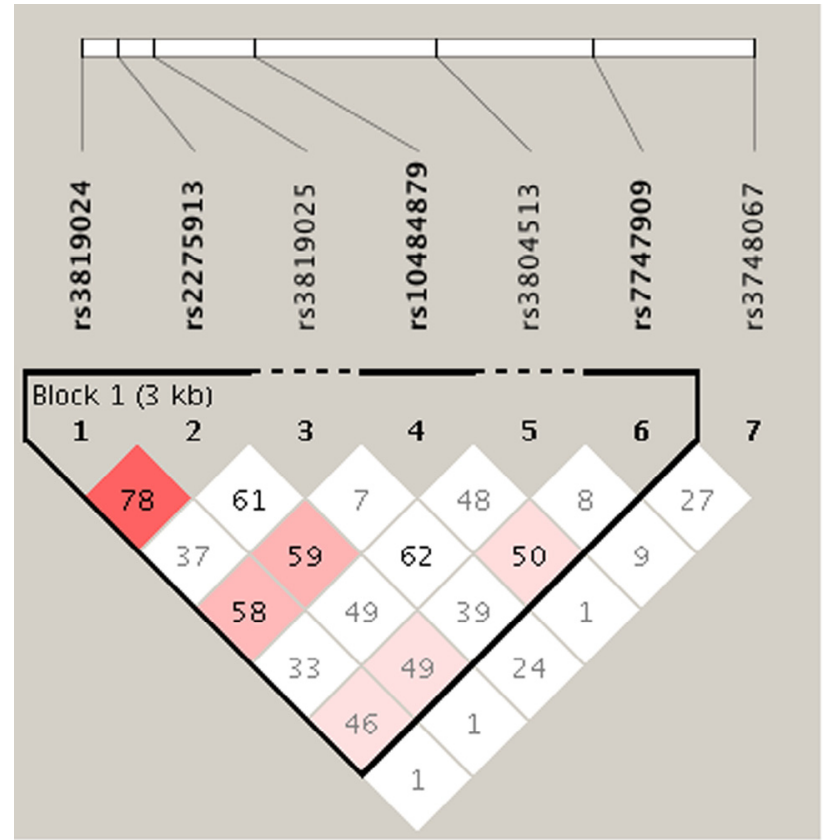

Fig. 1. Linkage disequilibrium (LD) map of $I L-17 A$ SNPs genotyped by Haploview. The positions of the SNPs (Build 37.3) are displayed above the Haploview output. The relative LD between any pair of SNPs is indicated by the color scheme, which represents LD relationships, which is based on D'values (normalized linkage disequilibrium measure or D) multiplied by 100 ; D' is calculated as D divided by the theoretical maximum for the observed allele frequencies. Values approaching zero indicate no LD, and those approaching 100 indicate complete LD. The square colored red represent varying degrees of LD $<1$ and LOD (logarithm of odds) $>2$ scores; darker shades indicating stronger LD.

Table 5

Haplotype frequencies across the $I L-17 A$ SNPs. ${ }^{\text {a }}$

\begin{tabular}{lllll}
\hline Haplotype $^{\text {b }}$ & Frequency & Case, Control frequencies & $\chi^{2}$ & $P$ \\
\hline A G C G & 0.652 & $0.634,0.679$ & 2.081 & 0.149 \\
G A T A & 0.068 & $0.064,0.074$ & 0.393 & 0.531 \\
G G C G & 0.066 & $0.060,0.076$ & 0.999 & 0.318 \\
A G C A & 0.056 & $0.046,0.072$ & 2.915 & 0.088 \\
A G T G & 0.036 & $0.058,0.004$ & 19.871 & $8.28 \times 10^{-6}$ \\
G A C G & 0.034 & $0.038,0.028$ & 0.761 & 0.383 \\
G A T G & 0.020 & $0.028,0.009$ & 4.401 & 0.036 \\
\hline
\end{tabular}

${ }^{\mathrm{a}}$ IL-17A block contains rs3819024, rs2275913, rs10484879, rs7747909.

b Bold underlined indicate minor allele.

17A SNPs analyzed, higher MAF of rs10484879 $(P<0.001)$ was seen in CRC cases than in control subjects. MAF of the remaining five tested variants were comparable between CRC patients and control subjects. Carriage of rs10484879 minor allele correlated with positive family history of CRC and other cancers $(P=0.002)$, CRC staging $(P=0.044)$, CRC treatment $(P=0.038)$, and with chemo body reaction $(P=0.001)$.

The distribution of $I L-17 A$ genotypes in CRC patients and control subjects are listed in Table 3. Significant differences in the distribution of $I L-17 A$ rs10484879 $(P<0.001)$ genotypes were seen between CRC cases compared to control subjects. The association of $I L-17 A$ rs10484879 with CRC persisted after controlling for gender, BMI, anemia, and smoking $(P=0.003)$. The risk of CRC associated with a specific $I L-17 A$ genotype was further confirmed by testing the effect of gender, BMI, anemia, and smoking as confounders. Results from Table 4 confirmed the association of rs10484879 with CRC under the codominant $(a P<0.001)$, dominant $(a P<0.001)$, and log-additive $(a P<$ 0.001) genetic models. In addition, rs3748067 was found to be associated with CRC under the codominant $(P=0.003)$ and dominant $(P=0.04)$ only. The association of both rs10484879 and rs3748067 with CRC was seen only in heterozygous carriers (Table 4)

\subsection{Haploview analysis}

Varied LD was noted between the even tested $I L-17 A$ variants, and further analysis was limited to only 4-locus (rs3819024-rs2275913rs10484879-rs7747909) (Fig. 1). Among these, common haplotype ( $>2 \%$ of total) seen in 7 of the possible 16 haplotypes. Haploview analysis identified the 4-locus $I L-17 A$ haplotypes AGTG $(P<0.011)$, and GATG $(P=0.036)$ to be positively associated with CRC (Table 5).

\section{Discussion}

Several studies highlighted the role of the immune system in gastrointestinal pathologies [25,26], including CRC [22,23,27]. In this regard, it was shown that a state of dysregulated anti-inflammatory and pro-inflammatory cytokine balance accompany the pathogenesis of CRC. Despite the central role of IL-17 in cancer pathogenesis [28-30], including CRC $[19,22]$, to our knowledge, few studies addressed the involvement of IL-17 in CRC in Tunisia, often with inconclusive findings. In this context, we analyzed the association between $I L-17 \mathrm{~A}$ rs3819024, rs2275913, rs3819025, rs10484879, rs7747909, and rs3748067 gene variants and the occurrence of CRC. Results obtained demonstrated positive association of $I L-17 A$ rs10484879 SNP and AGTG and GATG haplotypes with CRC. This is the first study that identifies the positive association of these haplotypes with increased risk of CRC.

Heightened IL-17 expression was documented for several tumors, including hepatocellular carcinoma [21], cervical cancer [31], lung cancer [32], bladder cancer [20], colorectal cancer [22], and others [19]. According to these studies, IL-17 facilitates tumor progression by inducing angiogenesis. For example, increased intra-tumor accumulation of IL-17A-producing cells was associated with an increased vasculogenesis in hepatocellular carcinoma [33], and increased intratumor Tc17 cell activity promoted vasculogenesis in cervical cancer [31]. Furthermore, elevated levels of IL-17A-producing cells was associated with increased lymphangiogenesis in lung cancer [34].

There is growing evidence that IL-17 can promote CRC progression, via an incompletely understood mechanism. It was shown that increased abundance of IL-17A-producing cells, and heightened expression of IL-17 facilitate CRC progression of by inducing a state of enhanced angiogenesis [19,22]. It was also suggested that CRC progression resulted from altered activity of Th17 cells, and/or imbalance of Th1/Th2 ratio [35]. This was highlighted by the findings that functional Th1 cells and Th17 cells clusters produce opposite effects on CRC patient survival, whereby strong Th17 expression was associated with poor cancer prognosis, when compared to strong Th1 profile, which was associated with prolonged and sustained CRC-free survival $[23,35]$. In contrast, Th2 did not predict prognosis [23].

Recruitment of CRC patients was based on clinico-pathological findings, which were obtained irrespective of family history, from clinical records of patients with colon and rectal cancer. On the other hand, control subjects were blood donors, or volunteers from the community, with no personal or CRC family history (CC or RC). Both modifiable (BMI, smoking) and non-modifiable (age, gender, ethnic background) factors contribute to CRC development. This was highlighted by the link of obesity with increased risk of CRC $[1,8,9]$, and by the association of weight gains during adulthood with heightened risk of colon cancer in men [8]. Accordingly, the contribution of key covariates to the association of IL-17A variants and haplotypes and overall CRC risk was addressed throughout the study.

In this retrospective case-control study, we investigated the association between CRC risk and the six $I L-17 A$ gene variants rs3819024, rs2275913, rs3819025, rs10484879, rs7747909, and rs3748067. IL$17 A$ gene is located on chromosome 6 , position $6 \mathrm{p} 12.2$, and contains 
857 polymorphic variants, distributed between near-gene (296), UTR (163), exonic (102), and intronic (296) variants. Positive association was seen between rs10484879 IL-17A gene variant, notably as heterozygous, and CRC. MAF of rs10484879 established for healthy Tunisians (9.7\%), while comparable to the global MAF (10.9\%), was markedly lower than that established for European (24.94\%) (www.ncbi.nlm.nih. gov/projects/SNP/snp), but higher than the frequencies seen in Asians $(<1.0 \%)$ and Africans (1.7\%). This reflects the genetic makeup of present-day Tunisians, who represent an admixture between original African (Berber) origin and invading Caucasians/Europeans throughout history. In contrast, none of the other genotypes was associated with altered risk of CRC. TO the best of our knowledge, this study is the first to confirm association between CRC and $I L-17 A$ rs10484879 gene variant.

Earlier studies reveal an association between IL-17A rs2275913 variant and cancers other than CRC, such as breast cancer [24], gastric cancer [15,16,21,36], bladder cancer [20], and cervical cancer [29,31]. A recent meta-analysis of 26 case-control studies, comprising 20 studies on Asians and 6 studies on Caucasians, and involving 7872 cases, confirmed that $I L-17 A$ rs2275913 (and $I L-17 F$ rs763780) polymorphisms is associated with increased risk for some (gastric, cervical, CRC), but not all (hepatocellular carcinoma) cancer types [37]. It is noteworthy that the association of rs2275913 with CRC was seen only under dominant genetic model, and was more pronounced in Asians than Caucasians [37]. This highlights the need for additional studies on related and distant populations aimed at establishing a role for the IL-17A rs2275913 as a genetic marker of CRC, and possibly associated features.

In our hands, there was lack of association between rs2275913 and CRC. This was in apparent disagreement with recent Tunisian [10], and Iranian [12] studies, which suggested an association between rs2275913 IL-17A gene variant and CRC. These apparent discrepancies are attributed to ethnic differences [12], bias in diagnosing CRC, and the study design. Furthermore, unlike our study which included 293 CRC patients, both studies of Omrani on Tunisians (102 CRC patients and 139 controls), and Nemati on Southern Iranian (202 patients and 203 controls) were smaller in size, and with the magnitude of the association obtained, this question the relevancy of the conclusions reached.

In addition, haploview analysis demonstrated the association of haplotypes AGTG and GATG with CRC. These were constructed based on the LD pattern established, which necessitated removal of rs3819025, rs3804513, and rs3748067 from the block, owing to absence of LD with remaining variants. Whereas previous studies identified select haplotypes associated with breast cancer [24], but not with CRC [12]. Difference between our results and those of Nemati are likely attributed to ethnic background (Iranian vs. Tunisian), sample size, and experimental interpretation [12].

\section{Conclusion}

In conclusion, our study showed a positive association $I L-17 A$ rs104284879, as well as AGTG and GATG haplotypes with CRC. Our study has strengths. First, cases and controls were ethnically assimilated, thus reducing the problems of genetic background differences. Second, we used tag-SNPs, thus increasing the coverage of $I L-17 A$ gene. However, our study had also limitations, namely the relatively limited sample size (293 patients) which did not allow for subgroup analysis, and did not provide for addressing cause-effect relationship, given its retrospective case-control design. In addition, some possible sources of heterogeneity, including selection of controls, and proper assessment of the contribution of lifestyle/environmental factors, were not explored. Follow-up studies on additional IL-17A SNPs, and populations of different ethnic origins are needed to confirm, or alternatively rule of the association of $I L-17 A$ SNPs with altered risk of CRC.

\section{Declarations of interest}

None.

\section{References}

[1] M. Bardou, A.N. Barkun, M. Martel, Obesity and colorectal cancer. Gut 62 (2013) 933-947.

[2] S.J. Heitman, P.E. Ronksley, R.J. Hilsden, B.J. Manns, A. Rostom, B.R. Hemmelgarn, Prevalence of adenomas and colorectal cancer in average risk individuals: a systematic review and meta-analysis, Clin. Gastroenterol. Hepatol. 7 (2009) 1272-1278.

[3] A.M. Arfaoui Toumi, L.I. Kriaa Ben Mahmoud, L.I. Khiari, A.H. Lahmer, L.A. Gharbi, M.O. Dhraïef, et al., Étude épidémiologique, anatomopathologique et évaluation des facteurs pronostiques de l'adénocarcinome colorectal mucineux vs non mucineux, La Tunisie Médicale, 88 (2010) 12-17.

[4] S. Faivre, G. Demetri, W. Sargent, E. Raymond, Molecular basis for sunitinib efficacy and future clinical development, Nat. Rev. Drug Discov. 6 (2007) 734-745.

[5] O. Jannasch, A. Udelnow, G. Romano, A. Dziki, D. Pavalkis, H. Lippert, P. Mroczkowski, International quality assurance project in colorectal cancer-unifying diagnostic and histopathological evaluation, Langenbecks Arch. Surg. 399 (2014) 473-479.

[6] P. Menéndez-Sánchez, P. Villarejo-Campos, D. Padilla-Valverde, J.M. MenéndezRubio, J.A. Rodríguez-Montes, Tumor markers in colorectal cancer Cir, Cir. 81 (2013) 169-175.

[7] J.P. Nougayrède, E. Oswald, Microbiote et cancer colorectal: des bactéries génotoxiques dans le tractus intestinal, Bull. Acad. Natl. Méd. 195 (2011) 1295-1305.

[8] A.G. Renehan, A. Flood, K.F. Adams, M. Olden, A.R. Hollenbeck, A.J. Cross, et al., Body mass index at different adult ages, weight change, and colorectal cancer risk in the National Institutes of Health-AARP Cohort, Am. J. Epidemiol. 176 (2012) $1130-1140$.

[9] R.C. Messina, S.D. Lane, C.J. Anderson, Body mass index and screening for colorectal cancer: gender and attitudinal factors, CancerEpidemiol. 36 (2012) 400-408.

[10] I. Omrani, R. Marrakchi, O. Baroudi, A. Mezlini, H. Ayari, I. Medimegh, et al., Significant association between interleukin-17A polymorphism and colorectal cancer, Tumour Biol. 35 (2014) 6627-6632.

[11] I. Omrani, O. Baroudi, K. Bougatef, A. Mezlini, A. Abidi, I. Medimegh, et al., Significant association between IL23R and IL17F polymorphisms and clinical features of colorectal cancer, Immunol. Lett. 158 (2014) 189-194.

[12] K. Nemati, H. Golmoghaddam, S.V. Hosseini, A. Ghaderi, M. Doroudchi, Interleukin-17F T7488 allele is associated with a decreased risk of colorectal cancer and tumor progression, Gene 561 (2015) 88-94.

[13] T. Korn, E. Bettelli, M. Oukka, V.K. Kuchroo, IL-17 and Th17 Cells, Annu. Rev. Immunol. 27 (2009) 485-517.

[14] Y. Kurebayashi, S. Nagai, A. Ikejiri, S. Koyasu, Recent advances in understanding the molecular mechanisms of the development and function of Th17 cells, Genes Cells 18 (2013) 247-265.

[15] X. Wu, Z. Zeng, B. Chen, J. Yu, L. Xue, Y. Hao, et al., Association between polymorphisms in interleukin-17A and interleukin-17F genes and risks of gastric cancer, Int. J. Cancer 127 (2010) 86-92.

[16] W.M. Zhao, P. Shayimu, L. Liu, F. Fang, X.L. Huang, X.L., Association between IL$17 \mathrm{~A}$ and IL-17F gene polymorphisms and risk of gastric cancer in a Chinese population, Genet. Mol. Res. 15 (2015), http://dx.doi.org/10.4238/gmr.15037864.

[17] P. Miossec, T. Korn, V.K. Kuchroo, Interleukin-17 and type 17 helper T cells, N. Engl. J. Med. 361 (2009) 888-898.

[18] M. Umemura, T. Kawabe, K. Shudo, H. Kidoya, M. Fukui, M. Asano, et al., Involvement of IL-17 in Fas ligand-induced inflammation, Int. Immunol. 16 (2004) 1099-1108.

[19] D. Wu, P. Wu, Q. Huang, Y. Liu, J. Ye, J. Huang, Interleukin-17: a promoter in colorectal cancer progression, Clin. Dev. Immunol. 2013 (2013) 436307.

[20] B. Zhou, P. Zhang, Y. Wang, S. Shi, K. Zhang, H. Liao, L. Zhang, Interleukin-17 gene polymorphisms are associated with bladder cancer in a Chinese Han population, Mol. Carcinog. 52 (2012) 871-878.

[21] X. Zhang, L. Zheng, Y. Sun, X. Zhang, Analysis of the association of interleukin-17 gene polymorphisms with gastric cancer risk and interaction with Helicobacter pylori infection in a Chinese population, Tumor Biol. 35 (2014) 1575-1580.

[22] J. Liu, Y. Duan, X. Cheng, X. Chen, W. Xie, H. Long, et al., IL-17 is associated with poor prognosis and promotes angiogenesis via stimulating VEGF production of cancer cells in colorectal carcinoma, Biochem. Biophys. Res. Commun. 407 (2011) 348-354.

[23] M. Tosolini, A. Kirilovsky, B. Mlecnik, T. Fredriksen, S. Mauger, G. Bindea, et al., Clinical impact of different classes of infiltrating T cytotoxic and helper cells (Th1, Th2, Treg, Th17) in patients with colorectal cancer, Cancer Res. 71 (2011) 1263-1271.

[24] L. Wang, Y. Jiang, Y. Zhang, Y. Wang, S. Huang, Z. Wang, et al., Association analysis of IL-17A and IL-17F polymorphisms in Chinese Han women with breast cancer, PLOS ONE 7 (2012) e 34400.

[25] H. Lv, Y. Jiang, J. Li, M. Zhang, Z. Shang, J. Zheng, et al., Association between polymorphisms in the interleukin 10 promoter region and susceptibility to inflammatory bowel disease, Mol. Bio. Rep. 41 (2014) 1299-1310.

[26] H. Zhu, X. Lei, Q. Liu, Y. Wang, Interleukin-10-1082A/G polymorphism and inflammatory bowel disease susceptibility: a meta-analysis based on 17,585 subjects, Cytokine 61 (2013) 146-153. 
[27] T. Yu, Q. Lu, X.L. Qu, D.Z. Cao, Q. Yu, Clinical study on gastric cancer susceptibility genes IL-10 -1082 and TNF $\alpha$, Genet. Mol. Res. 13 (2014) 10909-10912.

[28] Z. Qinghai, W. Yanying, C. Yunfang, Z. Xukui, Z. Xiaoqiao, Effect of interleukin-17A and interleukin-17F gene polymorphisms on the risk of gastric cancer in a Chinese population, Gene 10 (2014) 328-332.

[29] Y. Quan, B. Zhou, Y. Wang, R. Duan, K. Wang, Q. Gao, et al., Association between IL17 polymorphisms and risk of cervical cancer in Chinese women, Clin. Dev. Immunol. 2012 (2012) 6.

[30] A. Rafiei, V. Hosseini, G. Janbabai, A. Ghorbani, A. Ajami, T. Farzmandfar, T, Polymorphism in the interleukin-17A promoter contributes to gastric cancer, World. J. Gastroenterol. 19 (2013) 5693-5699.

[31] Y. Zhang, F. Hou, X. Liu, D. Ma, Y. Zhang, B. Kong, et al., Tc17 cells in patients with uterine cervical cancer, PLoS One 9 (2014) e86812.

[32] X.F. Wang, Y.T. Zhu, J.J. Wang, D.X. Zeng, C.Y. Mu, Y.B. Chen, et al., The prognostic value of interleukin-17 in lung cancer: a systematic review with meta-analysis based on Chinese patients, PLoS One 12 (2017) e0185168.

[33] J.P. Zhang, J. Yan, J. Xu, X.H. Pang, M.S. Chen, L. Li, Increased intratumoral IL-17- producing cells correlate with poor survival in hepatocellular carcinoma patients, $\mathrm{J}$. Hepatol. 50 (2009) 980-989.

[34] X. Chen, J. Wan, J. Liu, W. Xie, X. Diao, J. Xu, et al., L'augmentation des cellules productrices d'IL-17 est corrélée avec une survie et une lymphangiogenèse médiocres chez les patients atteints de CPNPC, Cancer du Poumon 69 (2010) 348-354.

[35] N. Yoshida, T. Kinugasa, H. Miyoshi, K. Sato, K. Yuge, T. Ohchi, et al., A high ROR $\gamma \mathrm{T} / \mathrm{CD} 3$ ratio is a strong prognostic factor for postoperative survival in advanced colorectal cancer: analysis of helper T cell lymphocytes (Th1, Th2, Th17 and regulatory T cells), Ann. Surg. Oncol. 23 (2016) 919-927.

[36] T. Shibata, T. Tahara, I. Hirata, T. Arisawa, Genetic polymorphism of interleukin$17 \mathrm{~A}$ and $-17 \mathrm{~F}$ genes in gastric carcinogenesis, Hum. Immunol. 70 (2009) 547-551.

[37] Z.M. Dai, T.S. Zhang, S. Lin, W.G. Zhang, J. Liu, X.M. Cao, H.B. Li, M. Wang, X.H. Liu, K. Liu, S.L. Li, Z.J. Dai, Role of IL-17A rs2275913 and IL-17F rs763780 polymorphisms in risk of cancer development: an updated meta-analysis, Sci. Rep. 6 (2016) 20439. 